Vol 12, Issue 10, 2019

\title{
BIOSYNTHESIS, CHARACTERIZATION, AND ANTI-INFLAMMATORY STUDY OF HEMIGRAPHIS COLORATA LOADED SILVER NANOPARTICLES
}

\author{
LIJI THOMAS*, SALEENA MATHEW \\ School of Industrial Fisheries, Cochin University of Science and Technology, Ernakulam, Kerala, India. Email: lijicebil @gmail.com
}

Received: 27 July 2019, Revised and Accepted: 22 August 2019

\begin{abstract}
Objective: This study targeted at the synthesis, characterization, and evaluation of the anti-inflammatory effects of Hemigraphis colorata silver nanopartilces (HAgNPs).
\end{abstract}

Methods: The HAgNPs were photosynthesized and characterized by UV-visible spectroscopy. The in vitro anti-inflammatory properties of HAgNPs were assessed by evaluating inhibition of protein denaturation and membrane stabilization ability assay.

Results: HAgNPs exhibited an absorbance peak at $450 \mathrm{~nm}$, characteristic for AgNPs, and their sizes ranged from 20 to 90 nm. The anti-inflammatory potential of HAgNPs when compared with $H$. colorata extract suggests that the AgNPs along with polyphenols and flavonoids from $H$. colorata can act as reducing or inhibiting agent on the release of acute inflammatory mediators.

Conclusion: The biologically synthesized HAgNPs could be of enormous use in the medical field for their proficient anti-inflammatory activity, which can be utilized as novel therapeutic agent for prevention and cure of inflammation due to biocompatible nature. This work clearly demonstrates HAgNPs as a budding source for anti-inflammatory drugs.

Keywords: Nanoscience, Hemigraphis colorata, Photosynthesis, Silver nanoparticles, Anti-inflammatory.

(C) 2019 The Authors. Published by Innovare Academic Sciences Pvt Ltd. This is an open access article under the CC BY license (http://creativecommons. org/licenses/by/4. 0/) DOI: http://dx.doi.org/10.22159/ajpcr.2019.v12i10.35116

\section{INTRODUCTION}

Indian traditional medicine, the oldest system, encompasses Ayurveda with numerous medicines based on metal mineral formulation, the herbo-metallic preparations with the particle diameter of 10-15 nm. Offers drug designing retaining contemporary perception of nanomedicine [1]. Silver used from prehistoric times for management of wounds, inflammation, and nanoparticles of silver industrialized with potent anti-inflammatory [2] and antioxidant activities [3]. The major phytochemicals responsible for spontaneous reduction of ions are flavonoids, terpenoids, carboxylic acids, aldehydes, ketones, and amides [4,5]. Consequently, the application of plants as potential biological nano-factories has a heap of interest due to ecological, energy-efficient, economic, and biocompatible nature suitable for pharmaceutical and biomedical applications [6,7]. Therefore, study on plant systems is considered to be a potential bioreactor for synthesis of metal nanoparticles without using toxic chemicals.

\section{Hemigraphis alternate (syn.) Hemigraphis colorata (Blume) H.G. Hallier (Acanthaceae)}

Oxidative stress and inflammation are critical factors attributed with delay in wound repairing process [8]. In this scenario, various phytochemicals from our "oldest savior" plants and its commodities appear to play as a therapeutic representative or prophylactic antidote [9]. The phytoconstituents of $H$. colorata are phenols, saponins, flavonoids, terpenoids [10], coumarins, carbohydrates, carboxylic acid, xanthoproteins, tannins, proteins, alkaloids, steroids, and sterol [11]. Since time immemorial, man has used various parts of this plant for treatment and prevention of many ailments [12]. Leaf paste of $H$. colorata was shown anti-inflammatory effect on carrageenaninduced paw edema model [13]. One of the acute responses; in wound healing is inflammation that results in coordinated influx of neutrophils at the wound site. Although commenced as a defensive, loss of regulation of this multifaceted progression can lead to several inflammatory disorders such as cancer, arthritis, and neurological diseases [14-16].
Liver damage, gastric lesions, initiation of cardiovascular problems, renal failure, fluid retention, bronchospasm, and prolongation of bleeding time are experienced in using anti-inflammatory drugs (nonsteroidal anti-inflammatory drugs [NSAIDs]) [17,18]. Hence, there is a growing interest in search for alternative medicinal plants, because of their chemical composition and better ability to mitigate mediators of multiple mechanisms to treat symptoms related to painful inflammatory process more effectively [19]. Prolonged inflammation delay natural healing process; a good healing agent should possess antiinflammatory activity for the proper wound $[13,20,21]$. The current study focused exploration of novel application of $H$. colorata for costeffective green synthesis of $H$. colorata silver nanoparticles (HAgNPs) in a simplistic way, to characterize and determine the efficacy of HAgNPs for treatment of inflammatory disease using in vitro studies.

\section{METHODS}

Plant collection and authentication

Healthy, disease-free, and plant leaves of $H$. colorata (Blume) collected from Ernakulam District, India and authenticated at Kerala Forest Research Institute, Peechi, Kerala.

\section{HAgNPs}

Green synthesis of HAgNPs

The synthesis of AgNP (HAgNP) was carried out by standard green synthesis procedures with slight modifications [22]. About $10 \mathrm{ml}$ of $H$. colorata extract was taken in a conical flask, and to the $40 \mathrm{ml}$ of $1 \mathrm{mM}$ $\mathrm{AgNO}_{3}$ (1:4 ratio of $\mathrm{H}$. colorata extract to $1 \mathrm{mM} \mathrm{AgNO}_{3}$ ) was added with constant stirring. The reaction was observed for change in color of the reaction mixture till $12 \mathrm{~h}$. The solution turned from yellowish to bright yellow and to dark brown indicating the AgNP formation. The changing in the color was observed gradually as it turned deep brown at the end of $24 \mathrm{~h} \mathrm{[23].}$ 


\section{Centrifugation}

AgNPs solution was centrifuged at $15,000 \mathrm{rpm}$ for $30 \mathrm{~min}$. The pellets were washed 3 times with $20 \mathrm{ml}$ of distilled water, to dispose of the free proteins/catalysts, remove any traces of unbound phytoconstituents that are not topping the AgNPs, and finally dried at $60^{\circ} \mathrm{C}$ in a dry oven, stored at $4^{\circ} \mathrm{C}[24]$

\section{Anti-inflammatory properties}

Inhibition of protein denaturation

Anti-inflammatory activity of the $H$. colorata aqueous extract and HAgNPs to inhibit protein denaturation was studied through in vitro assay carried out by method of [25], with minor modifications. To $50 \mu \mathrm{l}$ of different concentrations of tests, $5 \mathrm{ml}$ of $0.2 \% \mathrm{w} / \mathrm{v}$ bovine serum albumin (BSA) added, heated at $72^{\circ} \mathrm{C}$ for $5 \mathrm{~min}$ and then cooled for $10 \mathrm{~min}$.

$5 \mathrm{ml}$ of $0.2 \% \mathrm{w} / \mathrm{v}$ BSA solution with $50 \mu \mathrm{l}$ water used as control and aspirin $(100 \mu \mathrm{g} / \mathrm{ml})$ in water with $5 \mathrm{ml} 0.2 \% \mathrm{w} / \mathrm{v}$ BSA solution used as standard. The absorbance measured at wavelength $276 \mathrm{~nm}$.

$$
\% \text { inhibition }=\frac{\text { Abs control }- \text { Abs sample }}{\text { Abs control }} \times 100
$$

Membrane stabilization ability assay

Anti-inflammatory activity can be assayed by 2 methods [26-28]: (1) Inhibition of protein denaturation. (2) Membrane stabilization ability assay. Anti-inflammatory activity assay by membrane stabilization ability test is also appropriate title.

i. Preparation of red blood cells (RBCs) suspension

Blood collected in centrifuge tubes (from a healthy human volunteer who has not taken any NSAIDs for proceeding 2 weeks to experiment), centrifuged at $3000 \mathrm{rpm} 10 \mathrm{~min}$, washed thrice with normal saline and the remaining volume of blood measured and re-constituted as $10 \% \mathrm{v} / \mathrm{v}$ suspension with normal saline.

ii. Heat-induced hemolysis

The reaction mixture $(2 \mathrm{ml})$ consisted of $1 \mathrm{ml}$ test sample, $H$. colorata, and HAgNP different concentrations ( 250 and $500 \mu \mathrm{g} / \mathrm{ml}$ ) separately and $1 \mathrm{ml}$ of $10 \%$ RBCs suspension. Standard aspirin, saline is taken as control. Centrifuge tubes containing reaction mixture, incubated in water bath at $56^{\circ} \mathrm{C}, 30 \mathrm{~min}$, cooled under running tap water, followed by centrifugation at $2500 \mathrm{rpm}$ for $5 \mathrm{~min}$. The absorbance of the supernatants was measured at $560 \mathrm{~nm}$.

(Absorbance control -

Haemolysis percentage inhibition $=\frac{\text { Absorbance sample })}{\text { Absorbance control }} \times 100$

\section{Statistical analysis}

All data expressed as means \pm standard deviations calculated from three independent experiments.

\section{RESULTS}

Green synthesis of nanoparticles using biological agents has been an important sustainable approach for the biosynthesis of various forms of biocompatible nanoparticles. The method adopted for the synthesis of nanoparticles from $H$. colorata in this study is a bioreduction process in which $\mathrm{AgNO}_{3}$ was reduced to AgNPs. Formation of HAgNP was confirmed by the reduction of silver ions which was visibly evident from the color changes light yellow to dark brown of the solution associated with it.

\section{UV-visible spectrophotometric analysis}

HAgNP was subjected to initial characterization by UV-visible spectroscopy and $H$. colorata extract taken as a control. It is generally recognized that UV-visible spectroscopy could be used to examine size and shape of controlled nanoparticles in aqueous suspensions. This analysis exhibited a sharp absorbance at $450 \mathrm{~nm}$ (Fig. 1), particular for AgNPs. The control could not form the characteristic peak indicating that the reaction conditions were optimum with no abiotic reduction of $\mathrm{AgNO}_{3}$.

UV-visible spectra of $H$. colorata aqueous extract and HAgNP represent the formation of nanoparticles by $H$. colorata aqueous extract and showed the maximum absorption at a wavelength of $450 \mathrm{~nm}$.

In vitro anti-inflammatory analysis of $H$. colorata aqueous extract and HAgNP

Protein denaturation inhibition percentage

The anti-inflammatory activity or the ability of $H$. colorata aqueous extract and HAgNP to inhibit protein denaturation was studied

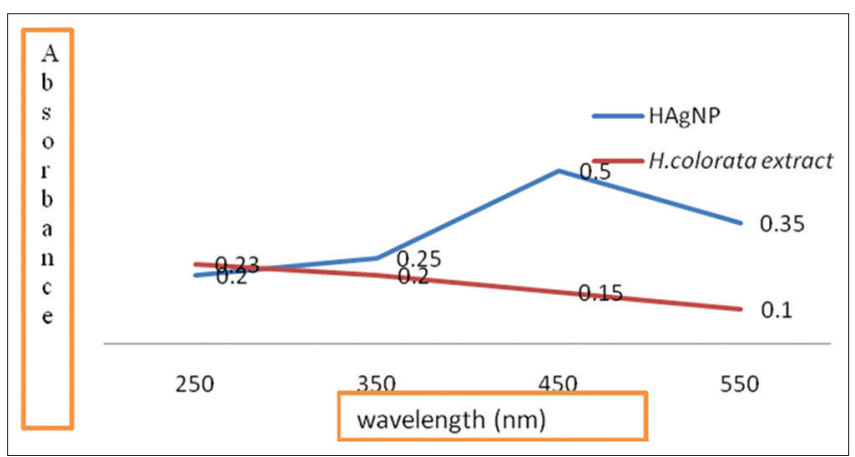

Fig. 1: UV-visible spectra of Hemigraphis colorata aqueous extract and $\boldsymbol{H}$. colorata silver nanoparticles

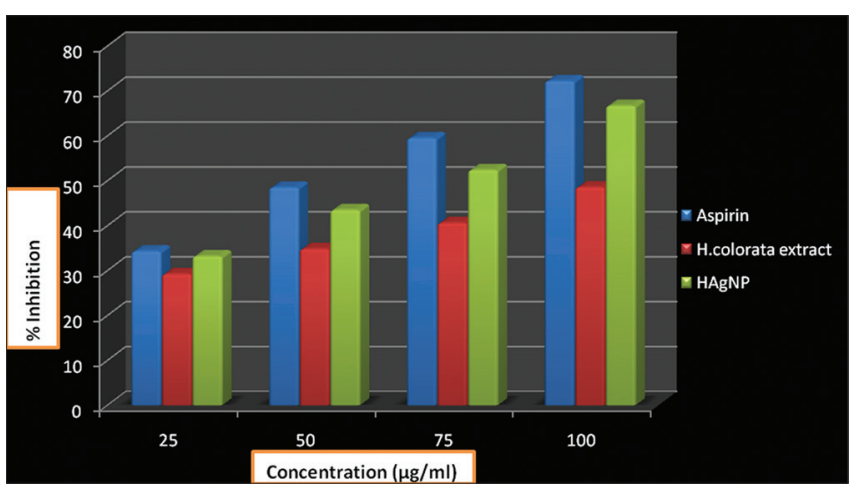

Fig. 2: In vitro anti-inflammatory activity of Hemigraphis colorata aqueous extract and $\boldsymbol{H}$. colorata silver nanoparticles (HAgNP) by protein denaturation analysis. HAgNP shows better activity than $H$. colorata aqueous extract alone

Table 1: Inhibition of hemolysis analysis of $\boldsymbol{H}$. colorata aqueous extract and HAgNP

\begin{tabular}{llll}
\hline S. No. & Sample & $\begin{array}{l}\text { Concentration } \\
(\boldsymbol{\mu g} / \mathbf{m l})\end{array}$ & $\begin{array}{l}\text { \% Inhibition } \\
\text { hemolysis }\end{array}$ \\
\hline 1. & Standard - Aspirin & 100 & $68.7 \pm 1.0$ \\
2. & H. colorata & 25 & $23.77 \pm 1.0$ \\
& aqueous extract & 50 & $27.6 \pm 1.3$ \\
& & 75 & $32.5 \pm 0.9$ \\
& & 100 & $39.67 \pm 1.7$ \\
3. & HAgNP & 25 & $24.7 \pm 1.0$ \\
& & 50 & $29.8 \pm 1.2$ \\
& & 75 & $36.8 \pm 1.2$ \\
& & 100 & $49.5 \pm 0.9$ \\
\hline
\end{tabular}

HAgNP showed almost similar results of standard aspirin and extract alone resulted in scarcer values signifying the encouraging anti-inflammatory activity of HAgNP. HAgNP: Hemigraphis colorata silver nanoparticles, H. colorata: Hemigraphis colorata 
through inhibiting heat-induced albumin denaturation. In vitro antiinflammatory activity of $H$. colorata aqueous extract and HAgNP at a concentration of $25-100 \mu \mathrm{g} / \mathrm{ml}$ was carried out by analyzing their ability to inhibit protein denaturation (Fig. 2). Denaturation of proteins is a well-established cause of inflammation. Albumin denaturation inhibition was highest in HAgNP than H. colorata aqueous extract at a concentration of $100 \mu \mathrm{g} / \mathrm{ml}$. The percentage inhibition rate exhibited by HAgNP is $66.7 \pm 1.2 \%$, and H. colorata extracts $55 \pm 1.9 \%$, both had given more than $50 \%$ inhibition. Aspirin, a standard anti-inflammatory drug showed the maximum inhibition, $76.2 \pm 0.9 \%$ at the concentration of $100 \mu \mathrm{g} / \mathrm{ml}$. H. colorata aqueous extract and HAgNP showed a dosedependent increase in percentage inhibition same as the control drug. The results of this investigation clearly show that HAgNP has better abilities than extract alone, can be explored in the search for natural anti-inflammatory drug.

\section{Membrane stabilization test}

Stabilization of the RBCs membrane was considered to further confirm the anti-inflammatory ability of $H$. colorata aqueous extract and HAgNP. The results of inhibition of hemolysis showed that HAgNP and extract at a concentration range of $25-100 \mu \mathrm{g} / \mathrm{ml}$ effective in inhibiting the heat-induced hemolysis and protect the erythrocyte membrane against lysis are shown in Table 1. H. colorata aqueous extract exhibited the maximum inhibition $39.67 \pm 1.7 \%$ and HAgNP $49.5 \pm 0.9 \%$ at $100 \mu \mathrm{g} / \mathrm{ml}$. Aspirin, a standard anti-inflammation drug showed the maximum of $68 \%$ at the concentration of $100 \mu \mathrm{g} / \mathrm{ml}$ (Table 1 ) and the biosynthesized HAgNP, was much effective in stabilization of the RBCs membrane than extract alone even at lower concentration of $25 \mu \mathrm{g}$.

\section{DISCUSSION}

In the current study, biosynthesis of HAgNPs was carried out using a bottom-up approach that mostly involves reduction/oxidation reactions that takes place in one step; therefore, compounds like plants which hold dual characteristics, i.e. reducing and capping agents are preferred [29] for the synthesis of shape and size-controlled nanoparticles. The improvement of resourceful green chemistry methods is employing for natural reducing, capping, and stabilizing agents like plant parts such as leaf [30] to organic AgNPs in ideal morphology and size.

\section{Analysis of HAgNP-color change}

The addition of extract to the silver nitrate solution changed the color of the solution from light yellow to dark brown, confirmed the reduction of silver nitrates into the silver nanoparticles HAgNP (Fig. 1). This color change has been observed earlier by several researchers [31]. Ibrahim [32] suggested that the color change appeared due to surface plasmon resonance of deposited AgNPs. This change in color of reaction mixture was considered as a primary indication for formation of AgNPs. In the current study, HAgNP may be synthesized by higher total phenolics content in $H$. colorata which are strong antioxidants with high reducing capacity [33]. The aqueous silver ions treated with herbal extracts reduced in solution, resulting in formation of silver hydrosols [34]. The higher content of total phenolic content in $H$. colorata leaves extract facilitates reduction of silver ions to nanoscalesized silver particles due to the electron-donating ability of phenolic compounds. The oxidation of the phenol group in leaf extract creates quinoid compound that can adsorb on surface of nanoparticles, ensuing their stabilization [35].

\section{HAgNP UV-visible spectroscopic analysis}

The biosynthesized HAgNPs primarily characterized by UV-visible spectroscopy. The absorbance at $450 \mathrm{~nm}$ recorded due to localized surface plasmon resonance and confirmed the formation of AgNPs (Fig. 2). When a specific wavelength is matched to the size of NPs dipole oscillation is generated, compensated form of inducing polarization and electrons in the NPs resonate, presenting a sturdy absorption [36]. Plant-based materials seem best candidates for eco-friendly largescale nanoparticles production, alternatives to chemical methods [29]. Characteristic absorbance peak of AgNPs is between 400 and $450 \mathrm{~nm}$. If the peak raises above $450 \mathrm{~nm}$, indicates aggregation or precipitation resulting particle with large size but if peak shifts below $400 \mathrm{~nm}$, the nano solution contains other participants such as impurities, organic species, and solvent [37]. The shift in absorption peak may be extremely indicative to size, morphology, quantity, and NPs growth, signifying the current study HAgNP is formed in adequate size and shape.

\section{In vitro anti-inflammatory activity}

Inhibition of albumin denaturation

Most biological proteins lose their efficacy when denatured. The ability of a substance to inhibit the denaturation of protein implies the obvious potential for anti-inflammatory activity. The capacity of $H$. colorata and HAgNP to inhibit protein denaturation of albumin was ranging from $48.55 \pm 1.9$ for $H$. colorata, $66.7 \pm 1.2$ for $\mathrm{HAgNP}$ against standard aspirin $76.2 \pm 0.9 \%$ inhibition in this assay had therefore provided another evidence for its promising anti-inflammatory properties at concentration of $100 \mu \mathrm{g} / \mathrm{ml}$. The results are almost similar [38,39].

\section{Membrane stabilization}

The human RBC membrane stabilization has been employed as a method to study in vitro anti-inflammatory activity of $H$. colorata extract and HAgNP, because the erythrocyte membrane is similar to the lysosomal membrane [40] and its stabilization entails that they may well stabilize lysosomal membranes. Maintenance of lysosomal membranes is substantial in averting the inflammatory reaction by checking the liberation of lysosomal components of activated neutrophil, such as bacterial enzymes and proteases, which forms further basis for tissue inflammation and damage on cellular discharge. The lysosomal enzymes released during inflammation are believed, related to acute or chronic inflammation. Results of H. colorata and HAgNP with maximum inhibition of $39.67 \pm 1.7$ for H. colorata, $49.5 \pm 0.9$ for HAgNP and $68.7 \pm 1.0$ for standard aspirin at a concentration of $100 \mu \mathrm{g} / \mathrm{ml}$ are comparable with [41] and are entitling $H$. colorata and particularly HAgNP with better results, as potent anti-inflammatory drug.

Results indicate that extracts of $H$. colorata and HAgNP possess excellent anti-inflammatory properties. It was formerly described AgNPs could successfully decrease the infiltration of inflammatory cells, obstruct the creation of inflammatory cytokines, upregulate the expression of matrix metalloproteinase and moreover, AgNPs possessed anti-inflammatory activity in post-operative peritoneal adhesion model [2]. These activities may be due to strong occurrence of polyphenolic compounds such as alkaloids, flavonoids, tannins, steroids, and phenols. The extract elements function as free radical inhibitors or scavengers by executing as primary oxidants, inhibited the heat-induced albumin denaturation and stabilized the RBCs membrane. Yilmaz et al. [42] showed that silver-polyvinyl pyrrolidone nanoparticles exhibited anti-inflammatory activity by reducing tumor necrosis factor- $\alpha$. The potential mechanism of AgNPs-mediated anti-inflammatory property was due to intracellular blocking of inflammatory pathways and downregulating pro-inflammatory cytokines [43]. It is well-known that in chronic and sub-acute inflammation, ROS play an important role in modulating extent of the inflammatory response, consequent tissue, and cell injury; antioxidants are considered as possible protecting agents reducing oxidative damage of the human body from ROS and retarding the progress of many diseases [44]. The results of previous in vitro antioxidant studies and quantitative determination of the total phenolic and flavonoids [45,46], strongly support the high antiinflammatory activity of HAgNPs like many other plants. From all these findings, HAgNP can be used as lead compound for designing a potent anti-inflammatory natural drug to be used for treatment of various ailments without side effects.

\section{CONCLUSION}

Green nanobiotechnology encompasses the practice of energyefficient ecological approaches for the production of nanoparticles using bio-sustainable approaches and biodegradable constituents. 
Current work demonstrates sustainable green synthesis of HAgNPs in an eco-friendly manner using aqueous extract of $H$. colorata leaf. Synthesis of HAgNP is owed to the higher content of total phenolic content in $H$. colorata leaf extract that expedites reduction of silver ions to AgNPs through electron-donating ability of phenolic compounds. The study demonstrated H. colorata, and especially HAgNP has significant anti-inflammatory activities, proved in the in vitro model. Experimental findings collectively show that HAgNPs are effective in reducing inflammation and accordingly delivers further indication that contributes to the understanding of the antiinflammatory properties and due to their biocompatible nature, propose HAgNPs as an innovative therapeutic agent for prevention and cure of inflammation.

\section{AUTHORS' CONTRIBUTIONS}

All the authors have contributed equally.

\section{CONFLICTS OF INTEREST}

There were no conflicts of interest.

\section{REFERENCES}

1. Khan MS, Ahmad I, Chattopadhyay D, editors. New Look to Phytomedicine: Advancements in Herbal Products as Novel Drug Leads. Academic Press; 2018

2. Wong KK, Cheung SO, Huang L, Niu J, Tao C, Ho CM, et al. Further evidence of the anti-inflammatory effects of silver nanoparticles. ChemMedChem 2009;4:1129-35.

3. Jayaraj RL, Tamilselvam K, Manivasagam $\mathrm{T}$, Elangovan $\mathrm{N}$. Neuroprotective effect of CNB-001, a novel pyrazole derivative of curcumin on biochemical and apoptotic markers against rotenoneinduced SK-N-SH cellular model of parkinson's disease. J Mol Neurosci 2013;51:863-70.

4. Prabhu S, Poulose EK. Silver nanoparticles: Mechanism of antimicrobial action, synthesis, medical applications, and toxicity effects. Int Nano Lett 2012;2:32.

5. Nargis S, Sumit D. Preliminary phytochemical screening and in vitro antimicrobial activity of the leaf extract of Thunbergia coccinea (Family Acanthaceae). Int J Curr Pharm Res 2019;11:111-4.

6. Abbai R, Mathiyalagan R, Markus J, Kim YJ, Wang C, Singh P, et al. Green synthesis of multifunctional silver and gold nanoparticles from the oriental herbal adaptogen: Siberian ginseng. Int J Nanomedicine 2016;11:3131-43.

7. Makarov VV, Love AJ, Sinitsyna OV, Makarova SS, Yaminsky IV, Taliansky ME, et al. "Green" nanotechnologies: Synthesis of metal nanoparticles using plants. Acta Naturae 2014;6:35-44

8. Yadav E, Singh D, Yadav P, Verma A. Antioxidant and anti-inflammatory properties of Prosopis cineraria based phenolic rich ointment in wound healing. Biomed Pharmacother 2018;108:1572-83.

9. Koley TK, Tiwari SK, Sarkar A, Nishad J, Goswami A, Singh B. Antioxidant potential of Indian eggplant: Comparison among white, purple and green genotypes using chemometrics. Agric Res 2019;8:9-20.

10. Sheu JR, Jayakumar T, Chang CC, Chen YC, Priya S, Ong ET, et al. Pharmacological actions of an ethanolic extracts of the leaves Hemigraphis colorata and Clerodendrum phlomoides. Clin Mol Med 2012;3:1-3.

11. Saravanan J, Joshi NH, Joshi VG, Sutar PS, Karigar AA. Wound healing activity of Hemigraphis colorata. Int J Contemp Res Rev 2010;1:1-3.

12. Chah KF, Eze CA, Emuelosi CE, Esimone CO. Antibacterial and wound healing properties of methanolic extracts of some Nigerian medicinal plants. J Ethnopharmacol 2006;104:164-7.

13. Subramoniam A, Evans DA, Rajasekharan S, Nair GS. Effect of Hemigraphis colorata (Blume) HG Hallier leaf on wound healing and inflammation in mice. Indian J Pharmacol 2001;33:283-5.

14. Rahman SM, Atikullah M, Islam MN, Mohaimenul M, Ahammad F, Islam MS, et al. Anti-inflammatory, antinociceptive and antidiarrhoeal activities of methanol and ethyl acetate extract of Hemigraphis alternata leaves in mice. Clin Phytosci 2019;5:16.

15. Lee HJ, Jeong HS, Kim DJ, Noh YH, Yuk DY, Hong JT, et al. Inhibitory effect of citral on NO production by suppression of iNOS expression and NF-kappa B activation in RAW264.7 cells. Arch Pharm Res 2008;31:342-9.

16. Nam NH. Naturally occurring NF-kappaB inhibitors. Mini Rev Med Chem 2006;6:945-51.
17. Jain NK, Kulkarni SK, Singh A. Modulation of NSAID-induced antinociceptive and anti-inflammatory effects by $\alpha 2$-adrenoceptor agonists with gastroprotective effects. Life Sci 2002;70:2857-69.

18. Uddin MJ, Rahman MM, Abdullah-Al-Mamun M, Sadik G. Vanda roxburghii: An experimental evaluation of antinociceptive properties of a traditional epiphytic medicinal orchid in animal models. BMC Complement Alternat med 2015;15:305.

19. Wang Q, Kuang H, Su Y, Sun Y, Feng J, Guo R, et al. Naturally derived anti-inflammatory compounds from Chinese medicinal plants. J Ethnopharmacol 2013;146:9-39.

20. Annan K, Houghton PJ. Antibacterial, antioxidant and fibroblast growth stimulation of aqueous extracts of ficus asperifolia miq. And Gossypium arboreum L. wound-healing plants of Ghana. J Ethnopharmacol 2008;119:141-4.

21. Barreto RS, Albuquerque-Júnior RL, Araújo AA, Almeida JR, Santos MR, Barreto AS, et al. A systematic review of the woundhealing effects of monoterpenes and iridoid derivatives. Molecules 2014; 19:846-62

22. Savithramma N, Rao ML, Rukmini K, Devi PS. Antimicrobial activity of silver nanoparticles synthesized by using medicinal plants. Int $\mathrm{J}$ ChemTech Res 2011;3:1394-402.

23. Awwad AM, Salem NM, Abdeen AO. Green synthesis of silver nanoparticles using carob leaf extract and its antibacterial activity. Int J Ind Chem 2013;4:29

24. Awwad AM, Salem NM. Green synthesis of silver nanoparticles by mulberry leaves extract. Nanosci Nanotechnol 2012;2:125-8.

25. Karthik I. Evaluation of anti-inflammatory activity of Canthium parviflorum by in-vitro method. Indian J Res Pharm Biotechnol 2013;1:729-30.

26. Sakat S, Juvekar AR, Gambhire MN. In vitro antioxidant and antiinflammatory activity of methanol extract of Oxalis corniculata Linn. Int J Pharm Pharm Sci 2010;2:146-55.

27. Oyedapo OO, Famurewa AJ. Antiprotease and membrane stabilizing activities of extracts of Fagara zanthoxyloides, Olax subscorpioides and Tetrapleura tetraptera. Int J Pharmacogn 1995;33:65-9.

28. Sadique J, Al-Rqobahs WA, Bughaith EI, Gindi AR. The bioactivity of certain medicinal plants on the stabilization of RBC membrane system. Fitoterapia 1989;60:525-32.

29. Mohanpuria P, Rana NK, Yadav SK. Biosynthesis of nanoparticles: Technological concepts and future applications. J Nanopart Res 2008;10:507-17.

30. Dubey SP, Lahtinen M, Sillanpää M. Green synthesis and characterizations of silver and gold nanoparticles using leaf extract of Rosa rugosa. Coll Surfaces A 2010;364:34-41.

31. Saxena A, Tripathi RM, Zafar F, Singh P. Green synthesis of silver nanoparticles using aqueous solution of Ficus benghalensis leaf extract and characterization of their antibacterial activity. Mater Lett 2012;67:91-4.

32. Ibrahim HM. Green synthesis and characterization of silver nanoparticles using banana peel extract and their antimicrobial activity against representative microorganisms. J Radiat Res Appl Sci 2015;8:265-75.

33. Pietta PG. Flavonoids as antioxidants. J Nat Prod 2000;63:1035-42.

34. Niveditha K, Sukirtha TH. Green synthesis, characterization and antimicrobial activity of silver nanoparticles from Plectranthus amboinicus plant extracts. Indian J Med Res Pharm Sci 2018;5:41-51.

35. Wang W, Chen Q, Jiang C, Yang D, Liu X, Xu S. One-step synthesis of biocompatible gold nanoparticles using gallic acid in the presence of poly-(N-vinyl-2-pyrrolidone). Coll Surfaces A 2007;301:73-9.

36. Mulvaney P. Surface plasmon spectroscopy of nanosized metal particles. Langmuir 1996;12:788-800.

37. Ayad ZM, Ibrahim OM, Omar LW. Biosynthesis and characterization of silver nanoparticles by Silybum marianum (silymarin) fruit extract. Adv Anim Vet Sci 2019;7:122-30

38. Osman NI, Sidik NJ, Awal A, Adam NA, Rezali NI. In vitro xanthine oxidase and albumin denaturation inhibition assay of Barringtonia racemosa $\mathrm{L}$. And total phenolic content analysis for potential antiinflammatory use in gouty arthritis. J Intercult Ethnopharmacol 2016;5:343-9.

39. Leelaprakash G, Dass SM. In vitro anti-inflammatory activity of methanol extract of Enicostemma axillare. Int J Drug Dev Res 2011;3:189-96.

40. Shenoy S, Kumar H, Thashma NV, Prabhu K, Pai P, Warrier I, et al. Hepatoprotective activity of Plectranthus amboinicus against paracetamol induced hepatotoxicity in rats. Int J Pharmacol Clin Sci 2012;2:32-8

41. Kumar S, Sharma UK, Sharma AK, Pandey AK. Protective efficacy 
of solanum xanthocarpum root extracts against free radical damage: Phytochemical analysis and antioxidant effect. Cell Mol Biol (Noisyle-grand) 2012;58:174-81

42. Yilmaz O, Ertoy Karagol IH, Bakirtas A, Topal E, Celik GE, Demirsoy MS, et al. Challenge-proven nonsteroidal anti-inflammatory drug hypersensitivity in children. Allergy 2013;68:1555-61.

43. Bhol KC, Schechter PJ. Effects of nanocrystalline silver (NPI 32101) in a rat model of ulcerative colitis. Dig Dis Sci 2007;52:2732-42.
44. Conner EM, Grisham MB. Inflammation, free radicals, and antioxidants. Nutrition 1996;12:274-7.

45. Dharmasoth RD, Ganga RB. Qualitative phytochemical screening and FTIR spectroscopic analysis of Grewia tilifolia (Vahl) leaf extracts. Int J Curr Pharm Res 2019;11:100-7.

46. Bidisha B, Sumit D. Preliminary phytochemical screening and to evaluate anti-oxidant property on root extract of Dillenia indica (elephant apple). Int J Curr Pharm Res 2019;11:128-33. 